\title{
Penile fracture and associated urethral injury: Experience at a tertiary care hospital
}

\author{
Attam Amit, MS; Kerketta Arun, MS; Behera Bharat, MS; Ram Navin, MS; Trivedi Sameer, MCh; \\ Dwivedi Udai Shankar, MCh
}

Department of urology, Institute of Medical sciences, Banaras Hindu University, Varanasi, Uttar Pradesh, India

Cite as: Can Urol Assoc J 2013;7:E168-E170. http://dx.doi.org/10.5489/cuaj.475

\section{Abstract}

Introduction: Penile fracture may be associated with urethral trauma in $1 \%$ to $38 \%$ of cases. We present our experience in treating 8 such cases.

Methods: Data were collected retrospectively from hospital records and from out-patient department follow-up visits.

Results: The mean age of the patients was 30.4 years; trauma during coitus was the most common cause of the penile fracture. One patient presented after 7 days. Two patients had normal examination of their penis despite typical history. All fractures were repaired on an emergency basis via subcoronal incision. In 2 patients with normal findings, the urethra had to be mobilized to locate the site of the injury. In 1 patient, the site of the urethral trauma was $1 \mathrm{~cm}$ away from the site of the corporal injury, which was localized by injecting sterile methylene blue per urethra. Postoperatively, all patients voided with good flow and had erections with adequate rigidity.

Conclusion: A high level of suspicion for urethral injury during surgical exploration is warranted, especially in the presence of suggestive history and examination.

\section{Introduction}

Penile fracture occurs when the erect penis is forcibly bent against resistance leading to a rupture of the corpora cavernosa. ${ }^{1}$ A history and clinical examination are the most important tools to diagnose penile fracture. Typical clinical presentation includes a snapping sound during the sexual act followed by immediate pain and penile detumescence, in addition to the emergence of large edema, hematoma and penile deformity. ${ }^{2}$ It may be associated with urethral trauma in $1 \%$ to $38 \%$ of cases. ${ }^{3,4}$ Associated urethral injury should be suspected if there is blood at meatus, hematuria and difficulty in voiding.

On examination, there is localized penile swelling with deviation to the opposite site. Careful palpation reveals a firm hematoma overlying the corporal defect on which penile skin can be rolled (or "rolling sign"). Extravasation outside the Buck's fascia can lead to a butterfly shaped hematoma in the perineum. ${ }^{2}$

We present our experience with 8 cases of penile fracture with associated urethral injury that were treated at our hospital.

\section{Methods}

A total of 34 cases of penile fracture were seen at the hospital emergency from July 2005 to July 2011. Out of these 34 patients, 8 had associated urethral injury. Data were collected retrospectively from hospital records and during out-patient department follow-up visits. An effort was made to keep all patients in active follow-up in the urology outpatient department.

All cases were explored on an emergency basis. Subcoronal incision was used in all cases with complete degloving of penis. Absorbable suture (polyglactin 4-0) was used for repair after refreshing the margins. All patients were catheterized with a $16 \mathrm{Fr}$ Foley catheter intraoperatively.

All patients were discharged with instructions to continue antibiotics and estradiol $0.05 \mathrm{mg}$ orally to prevent postoperative painful erections for 3 weeks. The indwelling urethral catheter was removed after the pericatheter contrast study ruled out any extravasation of dye at 2 weeks in all patients. The pericatheter study was performed by placing a 5 -Fr infant feeding tube by the side of the indwelling catheter and gently injecting the contrast medium with compression over the distal urethra.

\section{Results}

A total of 8 patients with penile fracture and associated urethral trauma were treated at our hospital (Table 1). Their ages ranged from 23 to 51 years (mean: 30.4). In 6 patients, penile fracture occurred during coitus and 2 patients had penile fracture due to penile manipulation. Only 3 patients pre- 


\begin{tabular}{lccc}
\hline \multicolumn{4}{l}{ Table 1. Patient characteristics } \\
\hline Serial no. & $\begin{array}{c}\text { Age } \\
\text { (years) }\end{array}$ & Etiology & $\begin{array}{c}\text { Delay at } \\
\text { presentation (days) }\end{array}$ \\
\hline 1 & 28 & Coitus & 1 \\
2 & 35 & Coitus & 4 \\
3 & 23 & Coitus & 1 \\
4 & 39 & Coitus & 3 \\
5 & 48 & Penile manipulation & 1 \\
6 & 36 & Coitus & 4 \\
7 & 51 & Penile manipulation & 7 \\
8 & 44 & Coitus & 6 \\
Mean & $\mathbf{3 0 . 4}$ & & $\mathbf{2 . 7}$ \\
\hline
\end{tabular}

sented within a day of penile trauma and 1 presented as late as 7 days after the penile trauma (mean duration: 2.7 days).

All 8 patients had a typical history of penile fracture. On examination, diagnosis of penile fracture was straightforward in 6 patients with typical findings. However, 2 patients, despite their suggestive history, did not have any external signs of penile trauma except for a vague area of corporal defect felt ventrally behind the urethra. On exploration, these patients did not reveal the area of corporal injury until the time the urethra was mobilized off the corpora cavernosa corresponding with the area of suspicion.

Ventral surface of the corpora was involved in all the cases. Corporal injury was located mostly in proximal corpora ( $6 / 8$ cases) and on the right side (5/8 cases). One patient had bilateral corporal injury and was associated with complete urethral disruption which was repaired after adequate mobilization of urethra to ensure tension-free anastomosis. The remaining urethral tears, which were partial in nature, were closed primarily with Vicryl 4'O interrupted sutures.

Urethral injury was suspected preoperatively on the basis of history in 6 patients as they had either difficulty voiding or bleeding per urethra. In the remaining 2 patients, urethral injury was detected intraoperatively near the site of corporal injury.

The area of the urethral trauma was close to the corporal defect in all but 1 patient, who had a urethral injury $1 \mathrm{~cm}$ away from the site of the corporal injury and was detected by injecting saline mixed with sterile methylene blue dye into urethra.

The postoperative course was uneventful. All patients were discharged by postoperative day 2 . Two patients were lost to follow-up after their voiding trial. The mean follow-up duration was 34.3 months (range: 1-55). All patients voided with good flow. Similarly, all patients achieved erections with adequate rigidity. One complained of pain during erection which subsided on follow-up. Two patients developed mild curvature of penis which did not hamper their sexual activity.

\section{Discussion}

Overall, $24 \%$ of patients of penile fracture had an associated urethral injury. Agarwal and colleagues reported a 23.5\% incidence of urethral injury with penile fracture. ${ }^{5}$ The most common cause of penile fracture with urethral injury in our patients was vaginal intercourse (75\%). Sexual intercourse is the most common cause of associated urethral injuries in most series. In Middle Eastern countries "Taqaandan" is the most common cause of penile fracture., ${ }^{2,5}$ Taqaandan, which comes from a Kurdish word meaning "to click," involves bending the top part of the erect penis while holding the lower part of the shaft in place, until a click is heard and felt. Taqaandan is said to be painless and has been compared to cracking one's knuckles. Taqaandan may be performed to achieve detumescence.

Patients usually present early because of the dramatic nature of the injury. However in our series, only 3 patients presented within a day of penile trauma and 1 presented as late as 7 days after penile trauma; this reflects the level of social stigma associated with such injuries. Although prompt surgery gives better aesthetic and functional results, surgery done even 7 days later gave good results provided care is taken to freshen the corporal margins before repair. ${ }^{6}$

Associated urethral injury should be suspected if there is blood at meatus, microscopic or gross hematuria and voiding difficulty. However, these symptoms may be absent in patients with associated urethral injury, as seen in 2 of our patients. ${ }^{6}$ Urinalysis is an important component in the diagnosis of suspected urethral injuries, but it can be misleading at times. In our series, 7 out of 8 patients with urethral injuries showed the presence of red blood cells on urinalysis, whereas Abdullah and colleagues reported the presence of microscopic hematuria in 6 out of 107 patients, but none of them had an urethral injury on exploration. ${ }^{7}$ Injuries involving the ventral aspect of corpora and associated spongiosal defect are likely to be missed on examination, as seen in 2 of our patients who only had a vague defect palpable in the corpora behind urethra, with a suggestive history (Fig. 1). Both patients had corporal injury on the ventral aspect between the urethra and corpora (Fig. 2).

Retrograde urethrogram is helpful in confirming the presence of a urethral injury. However, urethrography may give false negative results and is not recommended in routine practice. ${ }^{6}$ Mydlo and colleagues reported a false negative rate of $28.5 \%$ ( $2 / 7$ patients) in their small series. ${ }^{8}$ The cause for false negative urethrography is assumed to be the presence of overlying hematoma at the site of injury which masks the defect.

Diagnosis is usually clinical. We did not perform any radiologic investigations in any of our patients. Immediate 


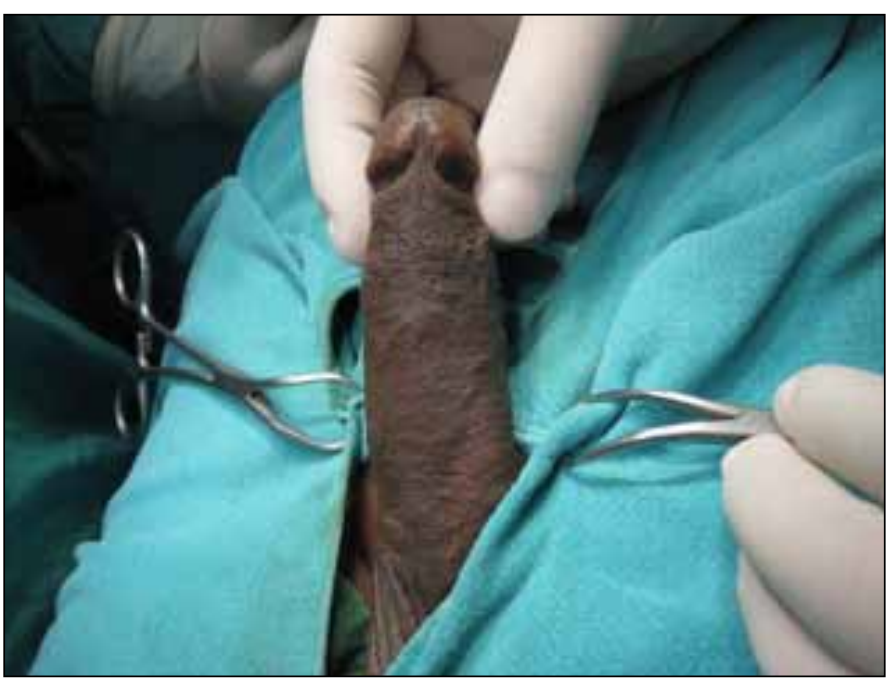

Fig. 1. Normal-looking penis in a patient with a history of a typical penile fracture with bleeding per urethra.

exploration with repair of the corporal tear is the standard and should be done in the presence of a typical history and supportive physical signs. ${ }^{6}$ One must avoid contact between the severed corpus spongiosum and corporal tissue to obviate the risk of postoperative impotence as a consequence of spongio-cavernosal fistula. The repair should involve complete evacuation of the hematoma, debridement of the margins, watertight closure of the tunica and spongiosum separately and wrapping of the urethral anastomotic site with a sub-dartos vascularised flap to prevent fistula formation in case of overlapping suture lines.

Of note, all patients, except 1 , had the site of the urethral trauma near the site of the corporal rupture. This patient had his urethral injury $1 \mathrm{~cm}$ away from the site of the corporal rupture, but it was detected because he had a history suggestive of urethral trauma leading us to actively look for it. Saline mixed with sterile methylene blue dye was injected into urethra and it was found to enter the operative field from the area of urethral injury. Shaeer investigated the value of methylene blue in locating urethral tears in fracture penis and found it reliable and safe. ${ }^{9}$

Our study has several limitations. It is a retrospective study of a descriptive nature on a small number of patients. The outcome measurements are subjective and postoperative erectile and voiding functions have not been assessed using validated tools.

\section{Conclusion}

While evaluating a patient with penile fracture, the possibility of urethral injury must always be kept in mind as its close proximity puts the urethra at risk. A high level of suspicion for urethral injury during surgical exploration is warranted

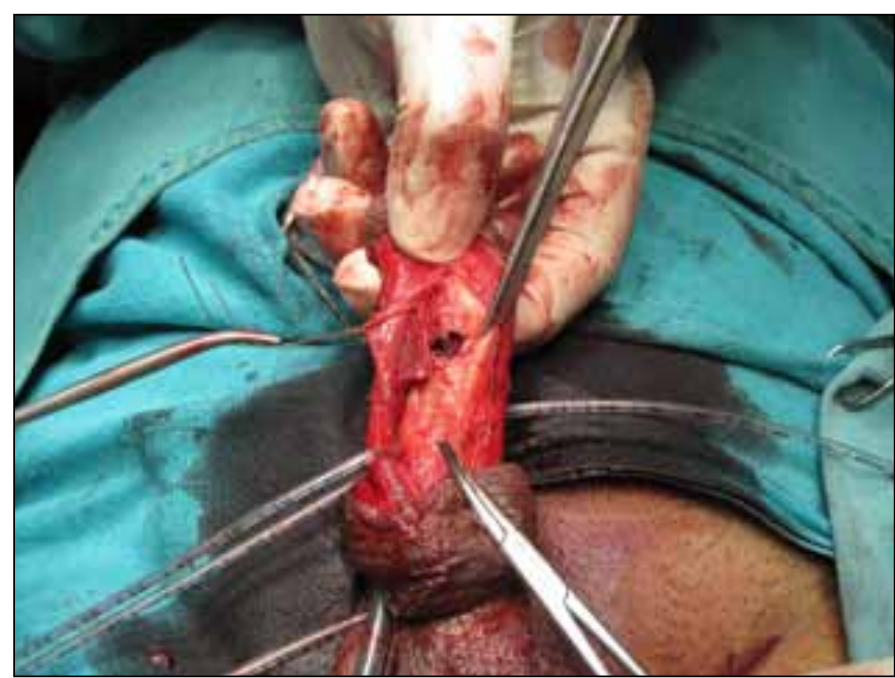

Fig. 2. Intraoperative picture: corporal injury on the ventral aspect between the urethra and corpora.

especially in the presence of suggestive history and examination. The site of urethral trauma usually overlies tear in the corpora. However, it may not be so and methylene blue is helpful in locating the site of urethral injury in such cases.

Competing interests: None declared.

This paper has been peer-reviewed.

\section{References}

1. Boncher NA, Vricella GJ, Jankowski JT, et al. Penile fracture with associated urethral rupture. Case Report Med 2010;2010:791948. http://dx.doi.org/10.1155/2010/791948

2. Eke N. Fracture of the penis. Br J Surg 2002;89:555-65. http://dx.doi.org/10.1046/i.13652168.2002.02075.x

3. Fergany AF, Angermeier KW, Montague DK. Review of Cleveland Clinic experience with penile fracture. Urology 1999;54:352-5. http://dx.doi.org/10.1016/S0090-4295(99)00115-6

4. Zargooshi J. Penile fracture in Kermanshah, Iran: report of 172 cases. J Urol 2000; 164:364-6. http:// dx.doi.org/10.1016/S0022-5347(05)67361-2

5. Agarwal MM, Singh SK, Sharma DK, et al. Fracture of the penis: a radiological or clinical diagnosis? A case series and literature review. Can J Urol 2009;16:4568-75.

6. Jack GS, Garraway I, Reznichek R, et al. Current Treatment Options for Penile Fractures. Rev Urol 2004;6:114-20.

7. Gedik A, Kayan D, Yami S, et al. The diagnosis and treatment of penile fracture: our 19-year experience. Ulus Travma Acil Cerrahi Derg 2011;17:57-60.

8. Mydlo JH, Hayyeri M, Macchia RJ. Urethrography and cavernosography imaging in a small series of penile fractures: a comparison with surgical finding. Urology 1998;51:616-9. http://dx.doi.org/10.1016/ S0090-4295(97)00701-2

9. Shaeer 0. Methylene blue-guided repair of fractured penis. J Sex Med 2006;3:349-54. http://dx.doi. org/10.1111/i.1743-6109.2005.00155.x

Correspondence: Dr. Sameer Trivedi, Department of Urology, Institute of Medical Sciences, Banaras Hindu University, Varanasi, Uttar Pradesh - 221005, India; drsameertrivedi@gmail.com 